\title{
Electrochemical Studies of New Donor-Acceptor Oligothiophenes
}

\author{
Marta Feroci, ${ }^{[a]}$ Tommaso Civitarese ${ }^{[a]}$ Fabiana Pandolfi, ${ }^{[a]}$ Rita Petrucci, ${ }^{\left[{ }^{[a]}\right.}$ Daniele Rocco, ${ }^{\left[{ }^{[a]}\right.}$ \\ Daniela Zane, ${ }^{[b]}$ Giuseppe Zollo, ${ }^{[a]}$ and Leonardo Mattiello*[a]
}

Electrochemical studies on a series of new conjugated oligothiophene derivatives are reported. The molecular architectures ( $D-A$ and $A-D-A$ ) of these compounds present different donor cores (thiophene, bithiophene) with different numbers of 3octylthiophene units (that act as $\pi$-bridge and solubilizing components). The acceptor end groups adopted were, in all the cases, ethyl cyanoacrylate units. The results from voltammetric experiments confirm the close relationship between the structure of these oligothiophenes and their electrochemical behavior. Furthermore, we carried out quantum mechanical

\section{Introduction}

The term "organic electronics" is used to indicate the vast field of science regarding the use of organic materials (either "small" molecules, oligomers or polymers) in electronic devices. ${ }^{[1-2]}$ Thiophene derivatives, especially in form of oligomers and polymers, surely fall in the class of the most studied (and used) organic semiconductor materials, probably because of their excellent charge transport properties and well-established synthetic procedures. ${ }^{[3]}$

There are countless applications of these materials in devices used as: OLEDs, ${ }^{[4,5]}$ Organic Photovoltaics, ${ }^{[6-10]}$ Sensors, ${ }^{[11]}$ OFET, ${ }^{[12]}$ Organic Photodetectors, ${ }^{[13]}$ and the number is continuously growing.

Polythiophenes were the first and most studied thiophene derivatives, and some of them are still today viewed as reference materials, but they present some intrinsic disadvantages such as the absence of well-defined chemical structures and, thus, of reproducibility. Instead, for the abovementioned applications, high grade of purity and synthetic reproducibility are requested, in order to clearly address the synthesis of materials with precise and specific properties.

[a] Prof. M. Feroci, Dr. T. Civitarese, Dr. F. Pandolfi, Prof. R. Petrucci,

Dr. D. Rocco, Prof. G. Zollo, Prof. L. Mattiello

Dept. of Basic and Applied Sciences for Engineering

Sapienza University of Rome

Via del Castro Laurenziano 7, 00161 Rome (Italy)

E-mail: leonardo.mattiello@uniroma1.it

[b] Dr. D. Zane

CNR-ISMN, Sapienza University of Rome

P.le Aldo Moro 5, 00185 Rome (Italy)

Supporting information for this article is available on the WWW under https://doi.org/10.1002/celc.201900920

An invited contribution to a Special Collection dedicated to Giornate dell'Elettrochimica Italiana 2019 (GEI2019) calculations to be able to obtain the HOMO/LUMO characteristics of some of our compounds in order to confirm our hypotheses on their electrochemical behavior. Moreover, the roles of the oligothiophene backbone and the ethyl cyanoacrylate group in cyclic voltammetry were elucidated by carrying out two different electrolyses at anodic and cathodic peak potentials. In particular, we were successful in the anodic dimerization of a tetrathiophene (D-A) to an octithiophene (A-D-A) (in high yield) with a considerable shortening of the chemical synthesis.
These requisites are fulfilled by oligothiophene derivatives: in many cases they possess better characteristics (physical, optical, electronic and self-assembly properties, possibility to work in solution, ease of purification, low-cost synthetic procedures, and so on) over their polymeric counterparts. ${ }^{[14]}$

Oligothiophenes can also be viewed, especially in the research field, as model compounds for the study of structureproperty relationships relatives to polythiophenes.

Dipolar push-pull (i.e.: molecules that present donor (D) and acceptor (A) moieties) chromophores with highly polarizable $\pi$ electron systems possess properties that result from the existence of photoinduced intramolecular charge transfers at low energies. ${ }^{[15]}$

In particular, thiophene oligomers possess extended $\pi$ electron delocalization along the backbone and are good holetransporting materials, and they can be synthesized with different Donor-Acceptor architectures (for example A-D or A-D-A type) in order to fine tuning their optical and electrochemical properties. ${ }^{[16]}$

In this paper we report an electrochemical study (cyclic voltammetry and electrolyses) on six oligothiophenes (with D-A and A-D-A molecular architectures) in which the acceptor end is an ethyl cyanoacrylate unit (Figure 1). The chemical synthesis of most of them was previously reported by us. ${ }^{[16]}$

\section{Results and Discussion}

In Figure 2 the cyclic voltammograms of studied oligothiophenes in $\mathrm{CH}_{2} \mathrm{Cl}_{2}-\mathrm{Bu}_{4} \mathrm{NBF}_{4}$ solutions are reported, while peak potential data are summarized in Table 1.

From the voltammetric curves in Figure 2, we can observe some similarities, i.e. compounds with only one EWG have irreversible anodic curves (probably due to anodic polymerization, vide infra), while compounds with two EWG have 


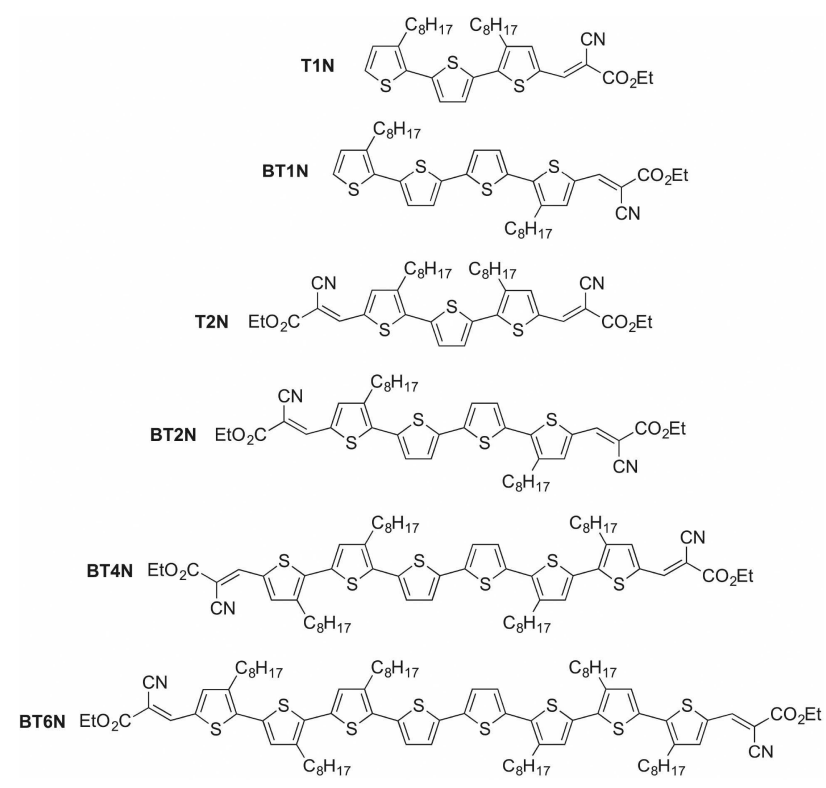

Figure 1. Structures of the studied oligothiophenes.

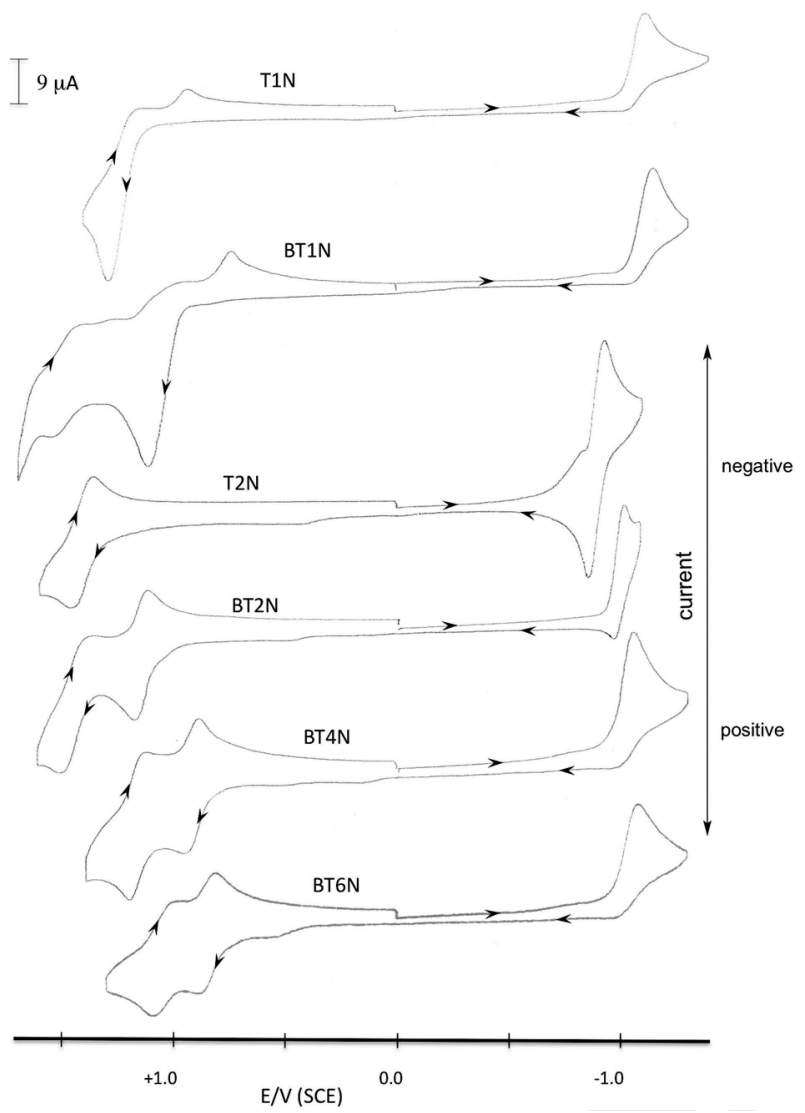

Figure 2. Cyclic voltammograms of oligothiophenes, $1 \times 10^{-3} \mathrm{M}^{\text {in } \mathrm{CH}_{2} \mathrm{Cl}_{2}^{-}}$ $0.1 \mathrm{M} \mathrm{Bu}_{4} \mathrm{NBF}_{4}$. Working electrode: GC. Reference electrode: SCE. $v=0.1 \mathrm{Vs}^{-1}$, $T=25^{\circ} \mathrm{C}$. Potential scan: 0 to negative end to positive end to $0 \mathrm{~V}$.

reversible anodic curves (having all terminal 2-positions blocked). On the side of cathodic reduction, all compounds (with the noteworthy exception of $\mathrm{T} 2 \mathrm{~N}$ ) have irreversible
Table 1. Voltammetric first anodic peak and first cathodic peak potentials ${ }^{[a]}$ for studied oligothiophenes.

\begin{tabular}{|lllll|} 
Compound $^{[a]}$ & $E_{\text {ox }}{ }^{1}[\mathrm{~V}]$ & $\mathrm{rev} / \mathrm{irr}^{[\mathrm{b}]}$ & $\mathbf{E}_{\mathrm{red}}{ }^{1}[\mathrm{~V}]$ & $\mathrm{rev} / \mathrm{irr}^{[\mathrm{b}]}$ \\
\hline T1N & +1.26 & $\mathrm{i}$ & -1.10 & $\mathrm{i}$ \\
BT1N & +1.10 & $\mathrm{i}$ & -1.14 & $\mathrm{i}$ \\
T2N & +1.40 & $\mathrm{r}$ & -0.90 & $\mathrm{r}$ \\
BT2N & +1.12 & $\mathrm{r}$ & -1.12 & $\mathrm{r}$ \\
BT4N & +0.94 & $\mathrm{r}$ & -1.04 & $\mathrm{i}$ \\
BT6N & +0.86 & $\mathrm{r}$ & -1.08 & $\mathrm{i}$ \\
\hline
\end{tabular}

[a] Cyclic voltammetry of oligothiophenes reported in Figure $2,1 \times 10^{-3} \mathrm{M}$ in $\mathrm{CH}_{2} \mathrm{Cl}_{2}-0.1 \mathrm{M} \mathrm{Bu}_{4} \mathrm{NBF}_{4}$. Working electrode: $\mathrm{GC}$. Reference electrode: SCE. $v=0.1 \mathrm{Vs}^{-1}, T=25^{\circ} \mathrm{C}$. [b] Nature of the peak: reversible ( $r$ ) or irreversible (i).

cathodic peaks, irrespective of the number of EWG and of thiophene rings present in the molecules.

In order to have insights into the voltammetric behavior of our functionalized oligothiophenes, ${ }^{[16]}$ we carried out a voltammetric analysis on simpler substrates. In fact, oligothiophene structures can be divided into two parts: a central core (the oligothiophene chain) and one or two electron-withdrawing ends. We thus decided to analyze the voltammetric behavior of $3,3^{\prime \prime \prime}$-dioctyl-2,2':5',2" $: 5^{\prime \prime}, 2^{\prime \prime \prime}$-quaterthiophene BT2T and of ethyl 2-cyano-3-(thiophen-2-yl)acrylate A (Figure 3).

The cyclic voltammogram of BT2T, under the experimental conditions previously reported (Figure 4), shows no cathodic peak and an irreversible anodic peak at $+1.08 \mathrm{~V}$. The irreversibility of this peak is most probably due to an anodic polymerization of this substrate, which possesses the terminal 2-positions without substituents and thus free to react (2position is more reactive of 3 -position in thiophene anodic polymerization). ${ }^{[17]}$

The opposite voltammetric behavior is obtained with A: no anodic peak and one cathodic peak at $-1.14 \mathrm{~V}$ (Figure 5).

On the bases of these results, we attribute the anodic electroactivity to the oligothiophene core of our substrates, and

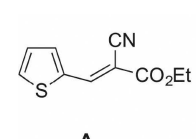

A

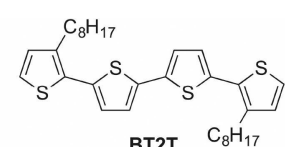

BT2т $\quad \mathrm{C}_{8} \mathrm{H}_{17}$
Figure 3. Structures of $A$ and BT2T.

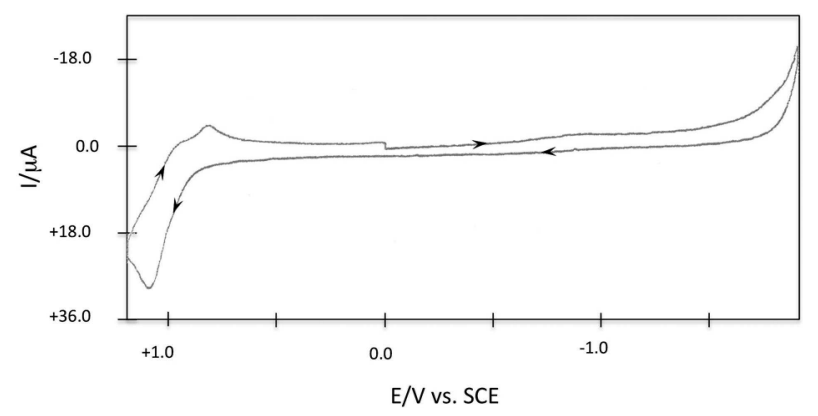

Figure 4. Cyclic voltammogram of BT2T $1 \times 10^{-3} \mathrm{M}$ in $\mathrm{CH}_{2} \mathrm{Cl}_{2}-0.1 \mathrm{M} \mathrm{Bu}_{4} \mathrm{NBF}_{4}$. Working electrode: GC. Reference electrode: SCE. $v=0.2 \mathrm{~V} \mathrm{~s}^{-1}, \mathrm{~T}=25^{\circ} \mathrm{C}$. Potential scan: 0 to -2.0 to +1.4 to $0 \mathrm{~V}$. 


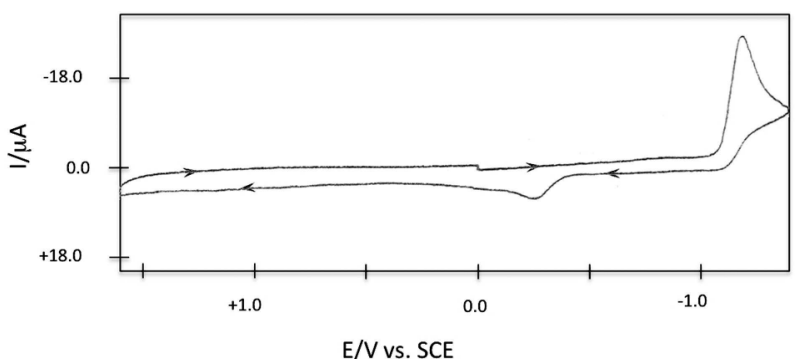

Figure 5. S Cyclic voltammogram of ethyl 2-cyano-3-(thiophen-2-yl)acrylate A $1 \times 10^{-2} \mathrm{M}$ in DMF-0.1 $\mathrm{M} \mathrm{Et}_{4} \mathrm{NBF}_{4}$. Working electrode: Pt. Reference electrode: SCE. $v=0.2 \mathrm{~V} \mathrm{~s}^{-1}, T=25^{\circ} \mathrm{C}$. Potential scan: 0 to -1.4 to +1.6 to $0 \mathrm{~V}$.

the cathodic activity to the cyanoacrylate portion of the molecule.

Moreover, in order to confirm the cathodic voltammetric behavior, we carried out the cathodic reduction of T1N in DMF$\mathrm{Et}_{4} \mathrm{NBF}_{4}$ solution at a potential of $-1.5 \mathrm{~V}$ (vs SCE). After $2.5 \mathrm{~F}$, usual workup gave product B in $74 \%$ yield (Scheme 1).

Product B derived from the classical Ziegler-Thorpe cyclization, ${ }^{[18]}$ whose cathodic version was previously reported by Utley ${ }^{[19]}$ and Fahmy. ${ }^{[20]}$ The proposed mechanism is depicted in Scheme 2. ${ }^{[19]}$

The formation of the cyclic product after cathodic reduction, with no alteration of the oligothiophene core, confirms that the cathodic peak is due mainly to the cyanoacrylate moiety. On the other hand, we cannot exclude the possibility of a charge delocalization when two EWGs are present, at least in the case of the shorter molecule $\mathbf{T} 2 \mathrm{~N}$, in which such a delocalization seems active, as indicated by the reversibility of the cathodic peak of $\mathrm{T} 2 \mathrm{~N}$ vs the irreversibility of $\mathrm{T} 1 \mathrm{~N}$. As regards the influence of the number of thiophene units and of alkyl chains on the cathodic peak potential, both molecule portions have a donor behavior and thus the increase of their number should render more negative the cathodic potential. This effect is confirmed by the comparison of the cathodic potentials of T1N and BT1N ( -1.10 and $-1.14 \mathrm{~V}$, respectively, Table 1) and of T2N and BT2N ( -0.90 and $-1.12 \mathrm{~V}$, respectively, Table 1$)$ as regards the donor effect of the thiophene rings, and of BT4N and D8N
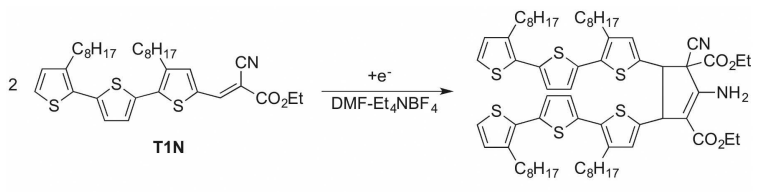

B

Scheme 1. Electrochemical reduction of T1N.

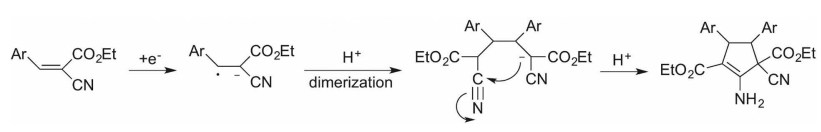

Scheme 2. Electrochemical reduction of ethyl arylcyanoacrylate. (vide infra) as regards the effect of the alkyl chains ( -1.04 and $-1.08 \mathrm{~V}$, respectively, Table 1$)$, which is less pronounced.

With regards to the anodic behavior of our molecules, the first anodic peak potential strongly depends on the number of thiophene rings, decreasing with the increase of ring number, thus confirming the donor effect of the thiophene rings. In fact, the first oxidation peak potential varies from $+1.10 \mathrm{~V}$ with four thiophene rings $(\mathrm{BT} 1 \mathrm{~N})$, to $+1.26 \mathrm{~V}$ with three $(\mathrm{T} 1 \mathrm{~N})$ to $>$ $+2.0 \mathrm{~V}$ when only one thiophene ring is present $(\mathrm{A})$, see Table 1. Analogous trend is obtained with oligothiophene with two EWG groups: $+0.86 \mathrm{~V}$ for eight rings (BT6N), $+0.94 \mathrm{~V}$ for six rings $(\mathrm{BT} 4 \mathrm{~N}),+1.12 \mathrm{~V}$ for four rings $(\mathrm{BT} 2 \mathrm{~N})$ and $+1.40 \mathrm{~V}$ for three rings (T2N), see Table 1 (although the number of alkyl chains present in the molecules are different in this series). It is worth noting that the first oxidation peak potential seems only slightly influenced by the presence of a EWG group: $+1.08 \mathrm{~V}$ for the tetrathiophene product BT2T and $+1.10 \mathrm{~V}$ for the same product with a cyanoacrylate group BT1N. Also the introduction of a second EWG group has little influence on the anodic potential, which is $+1.12 \mathrm{~V}$ for $\mathrm{BT} 2 \mathrm{~N}$.

As stated above, the nature of the anodic peak (reversible or irreversible) depends on the number of cyanoacrylate groups, which occupy the 2-position of the terminal thiophene rings. If this position is free, an anodic polymerization reaction subtracts oxidized product from its reduction at the electrode, rendering the peak irreversible. When the cyanoacrylate moiety occupies the reactive position, polymerization is hindered, and the peak is reversible.

Our results are in line with what reported in the literature on similar substrates (dicyanovinyl oligothiophenes). ${ }^{[21]}$

Furthermore, we carried out quantum mechanical calculations to be able to obtain the HOMO/LUMO characteristics of some of our compounds in order to confirm our hypotheses on their electrochemical behavior.

In particular, as regards the reversibility of the T2N reduction process compared with the substantial irreversibility of the same process concerning the other A-D-A type but longer-chain compounds, we hypothesized that the presence of the second acceptor group, only in the case of T2N which contains a shorter central chain with respect to other oligothiophenes (only three thiophene units), allows to stabilize the charge acquired after the first reduction process.

For longer chain oligothiophenes $(n \geq 4)$ the possible deviations from the planarity of the $\pi$ system (encouraged by the presence of octyl chains) can interrupt (partially or completely) the conjugation within the molecule, preventing the charge from stabilizing, thus making the radical anion susceptible to subsequent reactions chemical and therefore, in fact, making the reduction process irreversible.

This phenomenon is very well documented in the literature, ${ }^{[22]}$ with the only difference that here, our ethyl cyanoacrylate acceptor group, from an electrochemical point of view, can certainly be assimilated to the dicyanovinyl group considered in the cited article.

Quantum mechanical calculations were performed on some of our compounds, specifically on T1N, T2N and BT2N. For T1N and $\mathbf{T} 2 \mathrm{~N}$ (the derivatives with three thiophene units) the octyl 
chains have been replaced by methyl groups and for BT2N (four thiophene units) the octyl chains have been replaced by hydrogen atoms. Nevertheless, the results obtained have given us important information and confirmations with respect to our hypotheses and reference literature.

The HOMO/LUMO calculations for T1N and T2N, A-D and A-D-A type oligothiophenes, respectively, confirm (see Figure S2 and S3 in the Supporting Information) that, given the same length of the central chain, the addition of a terminal electron acceptor group causes a greater delocalization of the charge on the whole molecule and therefore a greater difficulty to oxidize $\left(\mathrm{E}^{\circ \mathrm{x}}{ }_{(\mathrm{T} 2 \mathrm{~N})}>\mathrm{E}_{(\mathrm{T} 1 \mathrm{~N})}^{\circ \mathrm{x}}\right)$ but, at the same time, a greater ease of reduction ( $\left.E_{(\mathrm{T} 2 \mathrm{~N})}^{\text {red }}<\mathrm{E}_{(\mathrm{T} 1 \mathrm{~N})}^{\text {red }}\right)$. As regards the reversibility of the $\mathrm{T} 2 \mathrm{~N}$ reduction process with respect to $\mathrm{T} 1 \mathrm{~N}$, in the same way, the greater delocalization of the charge over the whole molecule actually stabilizes the radical anion making it available to the subsequent oxidation process that occurs in the reverse sweep of the voltammetric curve.

The quantum mechanical data obtained for T2N and BT2N (both with A-D-A structures, three and four thiophene units in the central core, respectively) were also compared, which, as already mentioned, do not concern the real structures of the two compounds (with octyl chains) but of simplified structures, with methyl groups (T2N) and hydrogen atoms (BT2N). These data are in line with the reference literature, ${ }^{[23]}$ according to which, in the absence of steric hindrances caused by bulky alkyl chains and therefore in planarity conditions and with the same A-D-A molecular architecture, an increase in the number of thiophene units leads to a greater delocalization of the charge over the whole molecule (see Figure S4 and S5 in the Supporting Information).

Thus, in planar molecules, this leads to a stabilization that allows for quasi-reversible reduction processes for similar dicyanovinyl compounds containing three, four, five and six thiophene units. ${ }^{[23]}$

In our case, our hypothesis is that the presence of bulky octyl chains, for a number of thiophene units greater than or equal to four, leads to a torsion along the oligomeric chain and therefore to an out-of-plane deviation, with consequent lack of the reversibility of reduction processes.

To support this hypothesis, the fact that even the electrochemical bandgap $\left(E_{g}\right)$ is negatively influenced (thus, increased) by a lower conjugation along the central backbone ${ }^{[13]}$ is confirmed, in several cases, in our experimental data.

The presence of two octyl chains in the compound BT2N $\left(\mathrm{E}_{\mathrm{g}}\right.$ $\left({ }_{(\mathrm{BT} 2 \mathrm{~N})}=2.02 \mathrm{eV}\right)^{[16]}$ makes its bandgap higher than that of the corresponding dicyanovinyl derivative $\left(E_{g}=1.98 \mathrm{eV}\right)^{[23]}$ which has no alkyl chain. The presence of four octyl chains in the compound BT4N $\left(E_{g(B T 4 N)}=1.78 \mathrm{eV}\right)^{[16]}$ makes its bandgap higher than that of the corresponding dicyanovinyl derivative $\left(E_{g}=\right.$ $1.56 \mathrm{eV})^{[23]}$ which has no alkyl chain, and in this case the effect is even more pronounced, probably due to the greater number of alkyl chains. This hypothesis seems to be supported by the fact that the comparison between the bandgap of our two derivatives BT6N and D8N (vide infra, Scheme 3) that, with the same acceptor end groups and thiophene units (eight), differ only in the number of octyl chains (six for BT6N and four for

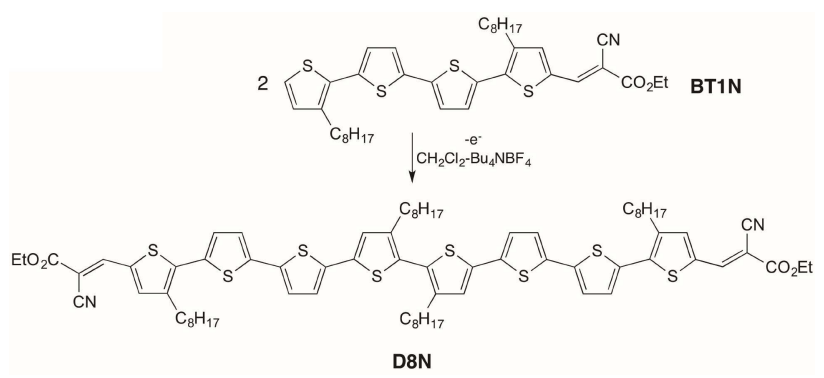

Scheme 3. Anodic dimerization of BT1N.

D8N), it is in favor (minor bandgap) of the derivative that presents a smaller number of alkyl groups, the compound D8N $\left(\mathrm{E}_{\mathrm{g}(\mathrm{BT} 6 \mathrm{~N})}=1.68 \mathrm{eV}\right.$ vs $\left.\mathrm{E}_{\mathrm{g}(\mathrm{D} 8 \mathrm{~N})}=1.58 \mathrm{eV}\right) .^{[16]}$

Finally, confirming that for shorter-chain oligothiophenes the presence of bulky alkyl groups has little or no effect on the planarity of the molecule, we observe that the bandgap of our oligothiophene $\mathbf{T} 2 \mathrm{~N}$ is even smaller $\left(\mathrm{E}_{\mathrm{g}(\mathrm{T} 2 \mathrm{~N})}=2.08 \mathrm{eV}\right)^{[16]}$ than that of the corresponding dicyanovinyl derivative $\left(E_{g}=\right.$ $2.19 \mathrm{eV})^{[23]}$ which has no alkyl chain. This fact is not surprising given that also an analogous compound, 5,5"-bi(dicyanovinyl)-

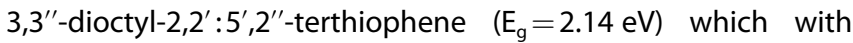
respect to $\mathbf{T} 2 \mathrm{~N}$ differs only in the type of electron acceptor groups (dicyanovinyl vs ethyl cyanoacrylate), has a lower bandgap than the corresponding dicyanovinyl derivative $\left(E_{g}=\right.$ $2.19 \mathrm{eV})^{[23]}$ which has no alkyl chain, highlighting, moreover, a quasi-reversible behavior of the reduction processes regarding

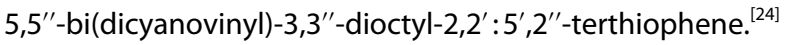

In order to explore the possibility of using electrochemistry as a synthetic tool to obtain high valuable long-chain oligothiophenes, and to shorten at the same time the multistep chemical synthesis, we considered the anodic dimerization of one of our newly synthesized oligothiophenes.

The choice fell on compound BT1N, a tetrathiophene that possess only one acceptor end group, leaving thus free for oxidation only a 2-position of the thiophene backbone. This compound was chosen also in view of the very long multi-step synthesis of the corresponding dimer.

To our knowledge, no long-chain $(>6)$ oligothiophene was synthesized by the means of anodic dimerization and fully characterized.

The anodic dimerization of BT1N (Scheme 3) gave the new octithiophene D8N in $61 \%$ yield (see Experimental Section).

Also this latter compound, D8N, was investigated by means of cyclic voltammetry (Figure 6) and its electrochemical behavior, not surprisingly, resembles that one possessed by the other octithiophene BT6N, that differs from D8N only for the number and the position of the octyl chains.

\section{Conclusions}

In this work we report electrochemical studies on a series of new oligothiophene derivatives possessing $D-A$ and $A-D-A$ molecular architectures. The number of thiophene rings, the 


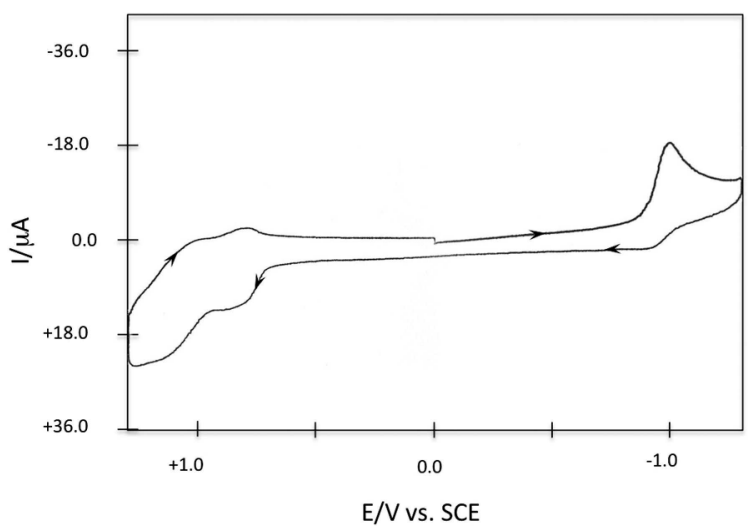

Figure 6. Cyclic voltammogram of D8N $1 \times 10^{-3} \mathrm{M}$ in $\mathrm{CH}_{2} \mathrm{Cl}_{2}-0.1 \mathrm{M} \mathrm{Bu}_{4} \mathrm{NBF}_{4}$. Working electrode: GC. Reference electrode: SCE. $v=0.1 \mathrm{~V} \mathrm{~s}^{-1}, T=25^{\circ} \mathrm{C}$. Potential scan: 0 to -1.3 to +1.3 to $0 \mathrm{~V}$.

backbone of these compounds, ranges from three to eight units, some of them carrying octyl chains for solubility reasons. The acceptor end groups were, in all the cases, ethyl cyanoacrylate units. The obtained results, both from voltammetric and electrolytic experiments, confirm the close (and predictable) relationship between their structure and their electrochemical behavior. In order to confirm our hypotheses based on their electrochemical behavior, we also carried out quantum mechanical calculations. Furthermore, an example is given of how electrochemistry can be useful (and more environmental-friendly, limiting the use of chemical reagents) as a synthetic tool for shortening multi-step chemical syntheses. Indeed, the synthesis of a new octithiophene derivative (D8N) by the means of anodic dimerization of the corresponding tetrathiophene in good yield is reported. The use of anodic dimerization as an easier and cleaner way to obtain long-chain fully conjugated oligothiophene derivatives is under development in our laboratory and will be the object of a subsequent work.

\section{Experimental Section}

\section{General Remarks}

Anhydrous $\mathrm{N}, \mathrm{N}$-dimethylformamide (DMF) and $\mathrm{CH}_{2} \mathrm{Cl}_{2}$ were commercially available and used as received. Tetraethylammonium tetrafluoroborate and tetrabutylammonium tetrafluoroborate were commercially available and kept under reduced pressure $12 \mathrm{~h}$ prior to use. Commercially available reagents were used without further purification. Flash column chromatography was carried out using Merck 60 kieselgel (230-400 mesh) under pressure. ${ }^{1} \mathrm{H}$ and ${ }^{13} \mathrm{C}$ NMR spectra were recorded at room temperature on a Bruker AC 200 spectrometer using $\mathrm{CDCl}_{3}$ as internal standard.

\section{Voltammetric Analysis}

Voltammetric measurements were performed using an Amel 552 potentiostat equipped with an Amel 566 function generator and an Amel 563 multipurpose unit in a three-electrode cell; the curves were displayed on an Amel 863 recorder; acquisition software was a CorrWare for Windows version 2.8d1 Scribner, elaboration software was a CorrView for Windows version 2.8d1 Scribner or with an Amel System 5000 electrochemical workstation. A 492/GC/ 3 Amel microelectrode was employed, using a Pt wire counter electrode and modified saturated calomel electrode as reference electrode (mSCE: SCE with organic solvent junction; the oxidation peak potential, on GC electrode, of ferrocene in DMF-0.1 M Et ${ }_{4} \mathrm{NBF}_{4}$ with this reference electrode is $E_{\text {oxFc }}=+0.46 \mathrm{~V}$ ).

\section{Quantum Mechanical Calculations}

First-principles calculations have been performed in the context of state of the art Density Functional Theory (DFT) using the Quantum Espresso suite. ${ }^{[25]}$ Troullier-Martins pseudopotentials ${ }^{[26]}$ have been employed and all the molecules have been fully relaxed using a plane wave basis set with an energy cutoff up to $100 \mathrm{Ry}$ and a cubic supercell ranging from $3 \mathrm{~nm}$ to $4 \mathrm{~nm}$. The exchangecorrelation functional employed is the PBE scheme of the generalized gradient approximation. The energy and force threshold values have been set to $E_{t h}=10^{-10}$ and $F_{\text {th }}=10^{-4}$ Ry respectively. A Grimme-d2 dispersion correction has been applied. ${ }^{[27]}$ The MO iso-surfaces drawn have been calculated at $10 \%$ of the maximum value of the MO probability density. The MO iso-levels have been calculated using 15 values of the MO probability density and have been drawn in the molecule plane.

\section{Synthesis of Ethyl 2-cyano-3-(thiophen-2-yl)Acrylate, A}

For the synthesis of ethyl 2-cyano-3-(thiophen-2-yl)acrylate A, a literature method $^{[28]}$ was followed, starting from thiophene-2carbaldehyde and ethyl cyanoacetate. The NMR spectra were in accordance with those reported in the literature. ${ }^{[29]} \mathrm{RF}: 0.5$, petroleum ether/ethyl acetate 90/10. ${ }^{1} \mathrm{H}$ NMR $\left(200 \mathrm{MHz}, \mathrm{CDCl}_{3}\right) 8.35$ $(\mathrm{s}, 1 \mathrm{H}), 7.84-7.79(\mathrm{~m}, 1 \mathrm{H}), 7.26-7.21(\mathrm{~m}, 1 \mathrm{H}), 4.37(\mathrm{~d}, J=7.1 \mathrm{~Hz}, 2 \mathrm{H})$, $1.39(\mathrm{t}, J=7.1 \mathrm{~Hz}, 3 \mathrm{H}) .{ }^{13} \mathrm{C} \mathrm{NMR}\left(50.3 \mathrm{MHz}, \mathrm{CDCl}_{3}\right)$ 162.6, 146.6, $137.2,136.0,135.2,128.6,115.7,99.3,62.5,14.2$.

\section{Electrochemical Reduction of Ethyl}

2-Cyano-3-(3,3'-dioctyl-[2,2' : $5^{\prime}, 2^{\prime \prime}$-terthiophen]-5-yl)Acrylate, T1N

Constant potential electrolysis was performed at $25^{\circ} \mathrm{C}$, using an Amel Model 552 potentiostat equipped with an Amel Model 731 integrator. The experiment was carried out in a divided glass cell separated through a porous glass plug filled up with a layer of gel

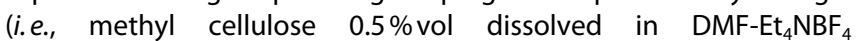
$1.0 \mathrm{~mol} \mathrm{dm}^{-3}$ ); Pt spirals (apparent area $0.8 \mathrm{~cm}^{2}$ ) were used as both cathode and anode. DMF-Et $\mathrm{NBF}_{4} 0.1 \mathrm{moldm}^{-3}$ was used as solvent-supporting electrolyte system (catholyte: $5 \mathrm{~cm}^{3}$; anolyte: $3 \mathrm{~cm}^{3}$ ), under nitrogen atmosphere; containing $0.15 \mathrm{mmol}$ of 2 -

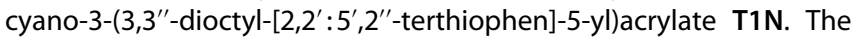
electrolysis potential was $-1.5 \mathrm{~V}$ (vs $\mathrm{mSCE}$ ). The electrolysis stopped after $37 \mathrm{C}(2.5 \mathrm{~F})$, and it was kept under stirring at $\mathrm{rT}$ for 12 hours. Usual workup and flash column chromatography (eluent: petroleum ether/ethyl acetate 90/10) gave diethyl 2-amino-3-cyano-4,5-bis (3", 4-dioctyl-[2,2' : 5', 2'--terthiophen]-5-yl)cyclopent-1-ene-1,3-dicarboxylate B (>90\% trans isomer) in $74 \%$ yield.

Diethyl 2-Amino-3-cyano-4,5-bis (3,3'-dioctyl-[2,2' :5',2' -terthiophen]-5-yl) cyclopent-1-ene-1,3-dicarboxylate, B

trans isomer: brownish oil (RF: 0.5, petroleum ether/ethyl acetate 80/20). ${ }^{1} \mathrm{H}$ NMR $\left(200 \mathrm{MHz}, \mathrm{CDCl}_{3}\right) 7.18(\mathrm{~d}, J=2.4 \mathrm{~Hz}, 1 \mathrm{H}), 7.16(\mathrm{~d}, J=$ 
$2.4 \mathrm{~Hz}, 1 \mathrm{H}), 7.05(\mathrm{~s}, 2 \mathrm{H}), 7.03-6.92(\mathrm{~m}, 5 \mathrm{H}), 6.69(\mathrm{~s}, 1 \mathrm{H}), 6.0(\mathrm{bs}, 2 \mathrm{H})$, $4.64(\mathrm{~d}, J=7.8 \mathrm{~Hz}, 1 \mathrm{H}), 4.50-4.34(\mathrm{~m}, 2 \mathrm{H}), 4.34(\mathrm{~d}, J=7.8 \mathrm{~Hz}, 1 \mathrm{H})$, 4.27-3.96 (m, 2H), 2.81-2.65 (m, 8H), 1.65-1.57 (m, 8H), $1.41(\mathrm{t}, J=$ $7.2 \mathrm{~Hz}, 3 \mathrm{H}), 1.37-1.13(\mathrm{~m}, 40 \mathrm{H}), 1.10(\mathrm{t}, J=7.1 \mathrm{~Hz}, 3 \mathrm{H}), 0.90-0.84(\mathrm{~m}$, 12H). ${ }^{13} \mathrm{C}$ NMR $\left(50.3 \mathrm{MHz}, \mathrm{CDCl}_{3}\right) \delta, 166.4,164.5,151.2,144.6,139.7$, 139.6, 139.4, 138.9, 136.4, 136.2, 135.7, 135.6, 135.6, 130.7, 130.4, $130.3,130.0,128.8,128.2,126.1,126.0,125.9,125.4,123.7,123.6$, $114.5,101.4,64.5,60.1,59.8,53.8,48.6,31.9,31.8,30.7,30.6,30.5$, $29.5,29.5,29.4,29.3,29.2,22.6,14.1$.

\section{Anodic Dimerization of Ethyl (E)-2-cyano-3-(3,3"'-dioctyl $\left[2,2^{\prime}: 5^{\prime}, 2^{\prime \prime}: 5^{\prime \prime}, 2^{\prime \prime \prime}\right.$-quaterthiophen]-5-yl)acrylate, BT1N}

Experimental Constant potential electrolysis was performed at $25^{\circ} \mathrm{C}$, using an Amel Model 552 potentiostat equipped with an Amel Model 731 integrator. The experiment was carried out in a divided glass cell separated through a porous glass plug filled up with a layer of gel (i.e., methyl cellulose $0.5 \%$ vol dissolved in DMF$\mathrm{Et}_{4} \mathrm{NBF}_{4} 1.0 \mathrm{~mol} \mathrm{dm}{ }^{-3}$ ); Pt spirals (apparent area $0.8 \mathrm{~cm}^{2}$ ) were used as both cathode and anode. $\mathrm{CH}_{2} \mathrm{Cl}_{2}-\mathrm{Et}_{4} \mathrm{NBF}_{4} 0.1 \mathrm{~mol} \mathrm{dm}^{-3}$ was used as solvent-supporting electrolyte system (catholyte: $5 \mathrm{~cm}^{3}$; anolyte: $5 \mathrm{~cm}^{3}$ ), under nitrogen atmosphere; containing $0.075 \mathrm{mmol}$ of ethyl

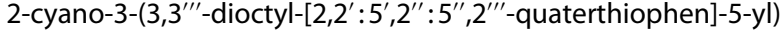
acrylate BT1N. The electrolysis potential was $+1.2 \mathrm{~V}$ (vs mSCE). The electrolysis stopped after $10 \mathrm{C}(1.4 \mathrm{~F})$. Usual workup and flash column chromatography (eluent: petroleum ether/dichloromethane 50/50) gave diethyl $3,3^{\prime}-\left(3,3^{\prime \prime \prime}, 3^{\prime \prime \prime \prime \prime \prime \prime \prime, ~} 4^{\prime \prime \prime \prime}\right.$-tetraoctyl$\left[2,2^{\prime}: 5^{\prime}, 2^{\prime \prime}: 5^{\prime \prime}, 2^{\prime \prime \prime}: 5^{\prime \prime \prime}, 2^{\prime \prime \prime \prime}: 5^{\prime \prime \prime \prime}, 2^{\prime \prime \prime \prime \prime}: 5^{\prime \prime \prime \prime \prime}, 2^{\prime \prime \prime \prime \prime \prime \prime}: 5^{\prime \prime \prime \prime \prime \prime \prime}, 2^{\prime \prime \prime \prime \prime \prime \prime \prime o c t i t h i o-~}\right.$ phene]-5, $5^{\prime \prime \prime \prime \prime \prime \prime \prime}$-diyl)(2E, $2^{\prime} E$ )-bis(2-cyano-acrylate) $\mathbf{D} 8 \mathrm{~N}$ in $61 \%$ yield.

Diethyl 3,3'-(3,3"', $3^{\prime \prime \prime \prime \prime \prime \prime \prime}, 4^{\prime \prime \prime \prime}-$ Tetraoctyl-[2, $2^{\prime}: 5^{\prime}, 2^{\prime \prime}: 5^{\prime \prime}, 2^{\prime \prime \prime}: 5^{\prime \prime \prime}$, $2^{\prime \prime \prime \prime}: 5^{\prime \prime \prime \prime}, 2^{\prime \prime \prime \prime \prime}: 5^{\prime \prime \prime \prime \prime}, 2^{\prime \prime \prime \prime \prime \prime \prime}: 5^{\prime \prime \prime \prime \prime \prime}, 2^{\prime \prime \prime \prime \prime \prime \prime \prime}-$ octithiophene]-5, $5^{\prime \prime \prime \prime \prime \prime \prime}$-diyl) (2E,2'E)-bis(2-cyano-acrylate), D8N

Dark violet solid with green metallic reflections, m.p.: $175-177^{\circ} \mathrm{C}$. ${ }^{1} \mathrm{H}$ NMR $\left(\mathrm{CDCl}_{3}\right) \delta$ (ppm): $0.89(12 \mathrm{H}, \mathrm{m}), 1.27(46 \mathrm{H}, \mathrm{m}), 1.67(8 \mathrm{H}, \mathrm{m})$, $2.84(8 \mathrm{H}, \mathrm{m}), 4.35(4 \mathrm{H}, \mathrm{q}, J=7.2 \mathrm{~Hz}), 7.19(10 \mathrm{H}, \mathrm{m}), 7.59(2 \mathrm{H}, \mathrm{s}), 8.22$ $(2 \mathrm{H}, \mathrm{s}) .{ }^{13} \mathrm{C}$ NMR $\left(\mathrm{CDCl}_{3}\right) \delta(\mathrm{ppm}): 14.27,14.38,22.83,29.41,29.51$, 29.59, 29.71, 29.85, 30.27, 32.04, 62.57, 97.85, 116.19, 124.33, 124.87, $126.53,126.87,128.78,129.50,133.08,133.50,136.12,139.54$, 140.69, 140.98, 146.10, 163.17. IR $v_{\max }\left(\mathrm{cm}^{-1}\right)$ (solid): 2919, 2849 $2214,1711,1576,1418,1240,1172,1084,777$.

\section{Acknowledgements}

This work was financially supported by Sapienza University of Rome. The authors want to thank Mr. Marco Di Pilato for technical support.

\section{Conflict of Interest}

The authors declare no conflict of interest.

Keywords: oligothiophenes - anodic dimerization - cathodic reduction $\cdot$ cyclic voltammetry $\cdot$ donor-acceptor
[1] Organic Electronics: Materials, Manufacturing and Applications (Ed.: $\mathrm{H}$. Klauk), Wiley-VCH, Weinheim, 2006.

[2] Organic Electronics II: More Materials and Applications (Ed.: H. Klauk), Wiley-VCH, Weinheim, 2012.

[3] G. Turkoglu, M. E. Cinar, T. Ozturk, Top. Curr. Chem. 2017, 375, 84. doi.org/10.1007/s41061-017-0174-z.

[4] J. Pei, J. L. Wang, X. Y. Cao, X. H. Zhou, W. B. Zhang, J. Am. Chem. Soc. 2003, 125, 9944-9945.

[5] I. F. Perepichka, D. F. Perepichka, H. Meng in Handbook of ThiopheneBased Materials (Eds.: I. F. Perepichka, D. F. Perepichka), Wiley-VCH, Weinheim, 2009, pp. 695-756. doi:10.1002/9780470745533.ch19

[6] Q. Zhang, B. Kan, F. Liu, G. Long, X. Wan, X. Chen, Y. Zuo, W. Ni, H. Zhang, M. Li, Z. Hu, F. Huang, Y. Cao, Z. Liang, M. Zhang, T. P. Russell, Y. Chen, Nat. Photonics 2015, 9, 35-41.

[7] Z. Li, G. He, X. Wan, Y. Liu, J. Zhou, G. Long, Y. Zuo, M. Zhang, Y. Chen, Adv. Energy Mater. 2012, 2, 74-77.

[8] Y. Chen, X. Wan, G. Long, Acc. Chem. Res. 2013, 46, 2645-2655.

[9] B. Kan, M. Li, Q. Zhang, F. Liu, X. Wan, Y. Wang, W. Ni, G. Long, X. Yang, H. Feng, Y. Zuo, M. Zhang, F. Huang, Y. Cao, T. P. Russell, Y. Chen, J. Am. Chem. Soc. 2015, 137, 3886-3893.

[10] L. Salamandra, L. La Notte, G. Paronesso, G. Susanna, L. Cinà, G. Polino, L. Mattiello, A. Catini, C. Di Natale, E. Martinelli, A. Di Carlo, F. Brunetti, T. M. Brown, A. Reale, Energy Technol. 2017, 131, 2168-2174.

[11] T. Sun, Q. Niu, Y. Li, T. Li, T. Hu, E. Wang, H. Liu, Sens. Actuators A 2018, 258, 64-71.

[12] C. Zhang, X. Zhu, Acc. Chem. Res. 2017, 50, 1342-1350.

[13] L. Zhang, N. S. Colella, B. P. Cherniawski, S. C. B. Mannsfeld, A. L. Briseno, ACS Appl. Mater. Interfaces 2014, 6, 5327-5343.

[14] Electronic Materials: The Oligomer Approach (Eds.: K. Müllen, G. Wegner), Wiley-VCH, Weinheim, 1998.

[15] F. Gala, L. Mattiello, F. Brunetti, G. Zollo, J. Chem. Phys. 2016, 144, 084310.

[16] F. Pandolfi, D. Rocco, L. Mattiello, Org. Biomol. Chem. 2019, 17, 30183025.

[17] Y. Wei, C.-C. Chan, J. Tian, G.-W. Jang, K. F. Hsueh, Chem. Mater. 1991, 3, 888-897 and references therein.

[18] The chemistry of cyclic enaminonitriles and o-aminonitriles (Eds.: E. C Taylor, A. McKillop), Interscience Publishers, New York, London, 1970

[19] N. C. Clarke, P. J. I. Runciman, J. H. P. Utley, J. Chem. Soc. Perkin Trans. 2 1987, 435-439.

[20] H. M. Fahmy, M. A. Aboutabl, L. I. Ibrahim, Indian J. Chem., Sect. B: Org. Chem. Incl. Med. Chem. 1994, 33, 657-661.

[21] M. S. Wrackmeyer, M. Hummert, H. Hartmann, M. K. Riede, K. Leo, Tetrahedron 2010, 66, 8729-8733.

[22] C. Koerner, H. Ziehlke, R. Fitzner, M. Riede, A. Mishra, P. Bäuerle, K. Leo in Advances in Polymer Science (Ed.: K. Leo), Springer International Publishing, 2016, pp. 51-75. doi: 10.1007/978-3-319-28338-8_3.

[23] R. Fitzner, E. Reinold, A. Mishra, E. Mena-Osteritz, H. Ziehlke, C. Körner, K. Leo, M. Riede, M. Weil, O. Tsaryova, A. Weiß, C. Uhrich, M. Pfeiffer, P. Bäuerle, Adv. Funct. Mater. 2011, 21, 897-910.

[24] Y. Liu, J. Zhou, X. Wan, Y. Chen, Tetrahedron 2009, 65, 5209-5215.

[25] P. Giannozzi, S. Baroni, N. Bonini, M. Calandra, R. Car, C. Cavazzoni, D. Ceresoli, G. L. Chiarotti, M. Cococcioni, I. Dabo, A. Dal Corso, S. de Gironcoli, S. Fabris, G. Fratesi, R. Gebauer, U. Gerstmann, C. Gougoussis, A. Kokalj, M. Lazzeri, L. Martin-Samos, N. Marzari, F. Mauri, R. Mazzarello, S. Paolini, A. Pasquarello, L. Paulatto, C. Sbraccia, S. Scandolo, G. Sclauzero, A. P. Seitsonen, A. Smogunov, P. Umari, R. M. Wentzcovitch, J. Phys. Condens. Matter 2009, 21, 395502.

[26] N. Troullier, J. Martins, Phys. Rev. B 1991, 43, 1993-2006.

[27] S. Grimme, J. Antony, S. Ehrlich, H. Krieg, J. Chem. Phys. 2006, 27, 17871799.

[28] F. Pandolfi, M. Feroci, I. Chiarotto, ChemistrySelect 2018, 3, 4745-4749.

[29] J. S. Yadav, B. V. Subba Reddy, A. K. Basak, B. Visali, A. Venkat Narsaiah K. Nagaiah, Eur. J. Org. Chem. 2004, 546-551.

Manuscript received: June 4, 2019

Revised manuscript received: July 15, 2019

Accepted manuscript online: July 29, 2019 